\title{
Low temperature near band edge recombination dynamics in $\mathrm{ZnO}$ nanorods
}

\author{
Z. N. Urgessa, J. R. Botha, Martin O. Eriksson, C. M. Mbulanga, S. R. Dobson, S. R. Tankio \\ Djiokap, K. Fredrik Karlsson, Volodymyr Khranovskyy, Rositsa Yakimova and Per-Olof \\ Holtz
}

\section{Linköping University Post Print}

N.B.: When citing this work, cite the original article.

Original Publication:

Z. N. Urgessa, J. R. Botha, Martin O. Eriksson, C. M. Mbulanga, S. R. Dobson, S. R. Tankio Djiokap, K. Fredrik Karlsson, Volodymyr Khranovskyy, Rositsa Yakimova and Per-Olof Holtz, Low temperature near band edge recombination dynamics in $\mathrm{ZnO}$ nanorods, 2014, Journal of Applied Physics, (116), 12, 123506.

http://dx.doi.org/10.1063/1.4896488

Copyright: American Institute of Physics (AIP) http://www.aip.org/

Postprint available at: Linköping University Electronic Press http://urn.kb.se/resolve?urn=urn:nbn:se:liu:diva-112055 


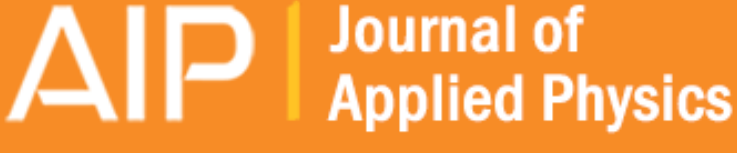

\section{Low temperature near band edge recombination dynamics in $\mathrm{ZnO}$ nanorods}

Z. N. Urgessa, J. R. Botha, M. O. Eriksson, C. M. Mbulanga, S. R. Dobson, S. R. Tankio Djiokap, K. F. Karlsson,

V. Khranovskyy, R. Yakimova, and Per-Olof Holtz

Citation: Journal of Applied Physics 116, 123506 (2014); doi: 10.1063/1.4896488

View online: http://dx.doi.org/10.1063/1.4896488

View Table of Contents: http://scitation.aip.org/content/aip/journal/jap/116/12?ver=pdfcov

Published by the AIP Publishing

\section{Articles you may be interested in}

The surface-plasmon-resonance and band bending effects on the photoluminescence enhancement of Agdecorated $\mathrm{ZnO}$ nanorods

J. Appl. Phys. 116, 063108 (2014); 10.1063/1.4892874

Surface related and intrinsic exciton recombination dynamics in $\mathrm{ZnO}$ nanoparticles synthesized by a sol-gel method

Appl. Phys. Lett. 102, 013109 (2013); 10.1063/1.4774002

Effect of annealing on the structural and luminescent properties of $\mathrm{ZnO}$ nanorod arrays grown at low temperature J. Appl. Phys. 109, 103508 (2011); 10.1063/1.3586243

Surface plasmon enhanced band edge luminescence of $\mathrm{ZnO}$ nanorods by capping Au nanoparticles Appl. Phys. Lett. 96, 071107 (2010); 10.1063/1.3323091

Surface recombination in $\mathrm{ZnO}$ nanorods grown by chemical bath deposition

J. Appl. Phys. 104, 073526 (2008); 10.1063/1.2991151

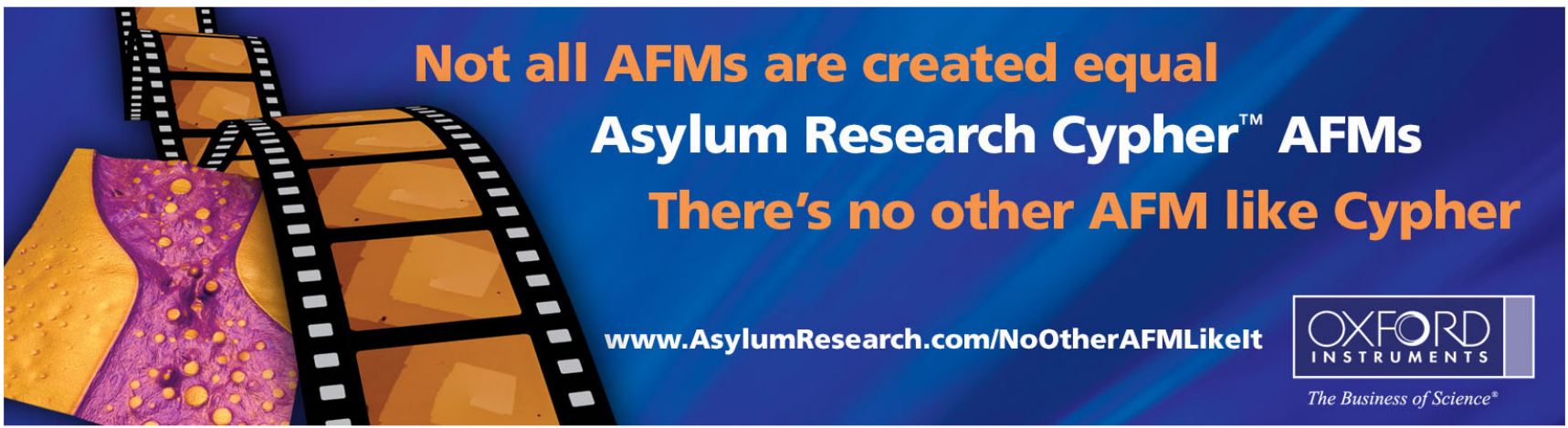




\title{
Low temperature near band edge recombination dynamics in $\mathrm{ZnO}$ nanorods
}

\author{
Z. N. Urgessa, ${ }^{1, a)}$ J. R. Botha, ${ }^{1}$ M. O. Eriksson, ${ }^{2}$ C. M. Mbulanga, ${ }^{1}$ S. R. Dobson, ${ }^{1}$ \\ S. R. Tankio Djiokap, ${ }^{1}$ K. F. Karlsson, ${ }^{2}$ V. Khranovskyy, ${ }^{2}$ R. Yakimova, ${ }^{2}$ and Per-Olof Holtz ${ }^{2}$ \\ ${ }^{1}$ Department of Physics, Nelson Mandela Metropolitan University, P.O. Box 77000, Port Elizabeth 6031, \\ South Africa \\ ${ }^{2}$ Departments of Physics, Chemistry and Biology (IFM), Linköping University, 58183 Linköping, Sweden
}

(Received 23 July 2014; accepted 15 September 2014; published online 24 September 2014)

\begin{abstract}
The recombination dynamics of neutral donor bound excitons $\left(\mathrm{D}^{\circ} \mathrm{X}: \mathrm{I}_{4}, \mathrm{I}_{6 / 6 \mathrm{a}}\right.$ ) and near band edge defect-related emission in solution grown $\mathrm{ZnO}$ nanorods are investigated using steady state and time-resolved photoluminescence (PL) measurements. The effects of annealing are also studied. Low temperature steady state PL shows a systematic removal of the $\mathrm{I}_{4}$ line after annealing at $450{ }^{\circ} \mathrm{C}$ and the subsequent domination of $\mathrm{I}_{6 \mathrm{a}}$ in these PL spectra. Additionally, the time decay of the $\mathrm{I}_{4}, \mathrm{I}_{6 / 6}$, free exciton (FX), and basal plane stacking fault-related (BSF) PL transitions are studied as a function of annealing temperature. For the various annealing temperatures studied, the PL decay is described by a bi-exponential profile with a fast component (contribution from the surface) and slow component (related to bulk recombination). The fast component dominates in the case of as-grown and low temperature annealed samples (anneal temperatures up to $300^{\circ} \mathrm{C}$ ), suggesting the presence of surface adsorbed impurities. For samples annealed above $400{ }^{\circ} \mathrm{C}$, the effects of the surface are reduced. The sample annealed at $850^{\circ} \mathrm{C}$ produced an overall enhancement of the crystal quality. The underlying mechanisms for the observed PL characteristics are discussed based on near surface band bending caused by surface impurities. (C) 2014 AIP Publishing LLC.
\end{abstract}

[http://dx.doi.org/10.1063/1.4896488]

\section{INTRODUCTION}

$\mathrm{ZnO}$, a semiconductor with extraordinary electronic, optical, and chemical properties, has received considerable attention for efficient light emitting devices operating in the near-ultraviolet (UV) and visible spectral ranges. ${ }^{1-8}$ In the context of utilizing $\mathrm{ZnO}$ in the optoelectronics industry, a thorough understanding of its optical and electrical properties is essential. In particular, a detailed understanding of carrier relaxation processes, which strongly affect its electronic and optoelectronic characteristics, is a prerequisite for the inclusion of $\mathrm{ZnO}$ in the optoelectronics sector. Carrier dynamics during generation and relaxation have been empirically studied by time resolved spectroscopy methods, such as low temperature time resolved photoluminescence (TRPL) spectroscopy. ${ }^{3,4}$ Depending on the growth method, material quality, and intentional dopants used, the low temperature photoluminescence (PL) spectra of $\mathrm{ZnO}$ are dominated by shallow donor bound excitons $\left(\mathrm{D}^{\mathrm{o}} \mathrm{Xs}\right),{ }^{1-3}$ free excitonic (FX), ${ }^{4}$ and/or defect-related transitions, particularly involving basal plane stacking faults (BSFs). ${ }^{5}$ Each of these recombination centers has different recombination/ relaxation characteristics. As a result, carrier relaxation processes in $\mathrm{ZnO}$, in particular, those involving $\mathrm{D}^{\circ} \mathrm{Xs}$, are still poorly understood. ${ }^{3}$ This situation arises from two main properties of $\mathrm{D}^{\circ} \mathrm{Xs}$ : firstly, there are $11\left(\mathrm{I}_{0}-\mathrm{I}_{10}\right)$ known $\mathrm{D}^{\circ} \mathrm{Xs}$ lines in $\mathrm{ZnO}^{4}$ It is known that these different $\mathrm{D}^{\circ} \mathrm{Xs}$ in $\mathrm{ZnO}$ have different exciton localization energies, thus influencing the capture/formation and lifetime of the exciton. ${ }^{3,6,7}$

\footnotetext{
a) Author to whom correspondence should be addressed. Electronic mail: zelalem.urgessa@nmmu.ac.za. Tel.: +27415042878. Fax: +27415042573.
}

Secondly, surface recombination strongly affects the luminescence decay profiles. ${ }^{3,8,9}$ The effect of the surface often manifests in a bi-exponential luminescence decay profile, given by $I(t)=A_{s} \exp \left(-t / \tau_{s}\right)+A_{b} \exp \left(-t / \tau_{b}\right)$, with a fast component $\left(\tau_{\mathrm{s}}\right)$ and slow component $\left.\left(\tau_{\mathrm{b}}\right)\right)^{3,9,10}$ Here, $I$ denotes the PL intensity and the pre-factors $\mathrm{A}_{\mathrm{s}} / \mathrm{A}_{\mathrm{b}}$ describe the contributions of the fast/slow component. ${ }^{3}$ The slow component is related to recombination in the bulk ${ }^{3,9}$ of the material, whereas the origin of the fast component is still under debate. ${ }^{3,8,9,11}$ For $\mathrm{D}^{\circ} \mathrm{X}$ related transitions, Wagner et al. ${ }^{7}$ have suggested that the fast decay component (non-radiative) is due to the capture of excitons on deeper traps and saturates when all traps are occupied. Recently, Chen et al. ${ }^{3}$ studied the recombination dynamics of shallow donor bound excitons in bulk $\mathrm{ZnO}$ and suggested that the fast component is associated with surface recombination.

Surfaces have been known to significantly affect the opto-electronic properties of a semiconductor. ${ }^{12-14}$ Because of the large surface-to-volume ratio, surface states play an even more prominent role in the PL properties of $\mathrm{ZnO}$ nanostructures, and, in particular, those of nanorods. Commonly reported surface adsorbed impurity species in $\mathrm{ZnO}$ includes $\mathrm{H}, \mathrm{OH}, \mathrm{H}_{2} \mathrm{O}, \mathrm{O}_{2}$, and HCOO. ${ }^{14-16}$ These impurities can be incorporated during growth, from the ambient, or by deliberate exposure to different gaseous environments. In particular, for nanostructures grown from solution (which is the case in this study); these species incorporate easily during growth. For example, Yang et al. ${ }^{8}$ studied the surface of chemical bath deposition (CBD)-grown $\mathrm{ZnO}$ using XPS and reported the presence of $\mathrm{OH}, \mathrm{H}$, and different oxygen containing groups (e.g., $\mathrm{O}_{2}$ ) on the surface of the nanorods. Clear features of the $\mathrm{O} 1 \mathrm{~s}$ core level were seen in the XPS spectra at 
binding energies of $530.4 \mathrm{eV}$ and $531.7 \mathrm{eV}$, corresponding to $\mathrm{O}-\mathrm{Zn}$ and $\mathrm{O}-\mathrm{H}$ bonds, respectively. ${ }^{8}$ Very recently, Liu et al. ${ }^{17}$ also observed $\mathrm{O}_{2}$ (with a binding energy of $533 \mathrm{eV}$ ) and $\mathrm{OH}$-related surface species after exposing hydrothermally grown $\mathrm{ZnO}$ nanorods to air for one year. Hence, the presence of surface adsorbed impurities on CBD-ZnO is expected, as various chemicals can be adsorbed to the surface at the relatively low growth temperature $\left(85^{\circ} \mathrm{C}\right)$ and due to the very nature of the CBD method. ${ }^{9}$ Irrespective of these findings, detailed investigations of the effects of the surface on the recombination dynamics of $\mathrm{ZnO}$ nanorods are lacking. The main purpose of this paper is then twofold: firstly, it is aimed at investigating the influence of the surface states on the low temperature dynamics of both the excitonic recombination and the BSF-related luminescence in solution-grown $\mathrm{ZnO}$ nanorods, and secondly it is aimed at contributing to the understanding of the effect of annealing on the low temperature PL characteristics of $\mathrm{ZnO}$ nanorods. Detailed TRPL and high resolution steady state PL spectroscopy studies were performed as a function of annealing temperature. It is well known that both steady state PL and TRPL spectroscopies are very sensitive tools for characterizing the radiative and non-radiative recombination processes in the materials, which are very helpful in understanding the optical performance of the materials. ${ }^{18}$ In this study, the steady state PL results clearly indicate a systematic removal of hydrogen-related donors and an evolution of other $\mathrm{D}^{\circ} \mathrm{X}$ lines with annealing temperature. The predominance of surface-related recombination in the case of samples annealed at lower temperatures, the suppression of this recombination channel for samples annealed above $400^{\circ} \mathrm{C}$, and the enhancement in overall crystalline quality for samples annealed at around $850{ }^{\circ} \mathrm{C}$ are shown and discussed in detail.

\section{EXPERIMENT}

Vertically aligned nanorods of $\mathrm{ZnO}$ on $\mathrm{Si}$ substrate were prepared by a two-step solution based process consisting of seed layer formation, followed by the growth of the nanorods. In the first step, a $5 \mathrm{mM}$ ethanol solution of zinc acetate dihydrate was spin coated onto pre-cleaned $\mathrm{Si}$ and subsequently annealed under pure oxygen flow for $30 \mathrm{~min}$ at $300^{\circ} \mathrm{C}$. The thermal decomposition of zinc acetate results in the formation of $\mathrm{ZnO}$ nanoparticles with diameters of around $5 \mathrm{~nm}$ on the substrate, ${ }^{19}$ which creates a seed layer for the $\mathrm{ZnO}$ nanorods. The rods were subsequently produced by immersion of the seeded substrate into a chemical bath containing an aqueous solution of $50 \mathrm{mM}$ zinc nitrate hexahydrate and $100 \mathrm{mM}$ hexamine. The growth time and temperature were fixed to $90 \mathrm{~min}$ and $85^{\circ} \mathrm{C}$, respectively. Scanning electron microcopy (SEM) was performed on the sample using a JEOL 7001F FE-SEM. To investigate the effect of surface adsorbed impurities, a sample was cleaved into smaller pieces and annealed in an oxygen rich environment for $30 \mathrm{~min}$ at temperatures ranging from $200^{\circ} \mathrm{C}$ to $900{ }^{\circ} \mathrm{C}$ in increments of $25^{\circ} \mathrm{C}$. Based on the observed changes in the line shape, peak positions, and intensities of the different emission lines, the annealed samples are classified into four groups: (i) low temperature annealed samples (i.e., samples annealed up to $300^{\circ} \mathrm{C}$ ), (ii) samples annealed between $300^{\circ} \mathrm{C}$ and $450^{\circ} \mathrm{C}$, (iii) samples annealed between $450^{\circ} \mathrm{C}$ and $800^{\circ} \mathrm{C}$, and (iv) samples annealed above $850^{\circ} \mathrm{C}$. For the steady state PL experiments, the samples were excited with the $325 \mathrm{~nm}$ line of a He-Cd laser at $11 \mathrm{~K}$ and the emission was dispersed with a high resolution Horiba monochromator (FHR 1000) and detected by a photomultiplier tube (R666S) with a GaAs photocathode. TRPL spectroscopy measurements were carried out at $5 \mathrm{~K}$. The $266 \mathrm{~nm}$ line from a tunable Ti:sapphire pulsed laser (repetition rate of $75 \mathrm{MHz}$, pulse duration of $0.2 \mathrm{ps}$, and spectral width of $1 \mathrm{~nm}$ ) was employed as an excitation source. The PL transients were recorded by a streak camera connected to a $0.5 \mathrm{~m}$ focal length, 150 grooves $/ \mathrm{mm}$ single grating monochromator (spectral resolution $1 \mathrm{~nm}$ and temporal resolution $5 \mathrm{ps}$ ). The laser power was varied from $1 \mu \mathrm{W}$ to $500 \mu \mathrm{W}$, but results obtained at $5 \mu \mathrm{W}$ are presented, as no significant changes were observed for different excitation powers.

\section{RESULTS}

Fig. 1(a) shows a typical SEM image of the $\mathrm{ZnO}$ nanorods, having an average diameter of $\sim 80 \mathrm{~nm}$. Fig. 1(b) displays typical $\mathrm{x}$-ray diffraction (XRD) spectra (normalized) of an as-grown sample and samples sequentially annealed between $300^{\circ} \mathrm{C}$ and $850^{\circ} \mathrm{C}$ in oxygen for $30 \mathrm{~min}$. An XRD spectrum was taken after each annealing step. As can be seen from the spectra, the as-grown sample is crystalline and there is no significant change with annealing temperature, since no changes were observed in the full-width at halfmaximum (FWHM) of the 0002 XRD peak.

Fig. 1(c) presents a near band edge (NBE) spectrum in the energy range between $3.28 \mathrm{eV}$ and $3.38 \mathrm{eV}$, obtained at $11 \mathrm{~K}$ for as-grown and low temperature annealed samples. In all cases, the spectra are dominated by a hydrogen related emission line at $3.3632 \mathrm{eV}(368.53 \mathrm{~nm})$, often referred to as $\mathrm{I}_{4}$. This line is considerably broader than what is typically reported for bulk material and has a pronounced low energy tail. The slight shift in the peak position from the wellknown position of the $\mathrm{I}_{4}$ line $(3.3628 \mathrm{eV})$ is due to the presence of unresolved lines on both energy sides, which will be discussed below. In addition to the broad $\mathrm{I}_{4}$ line, a structural defect-related emission line is seen at around $3.324 \mathrm{eV}$ for the as-grown sample and it red shifts to $3.322 \mathrm{eV}$ as the annealing temperature increases to $300^{\circ} \mathrm{C}$.

The spectra clearly show that the overall intensity of the emission significantly increases with annealing temperature. This result has been observed in several experiments performed over a period of time. As shown in Fig. 1(b), annealing does not affect the crystalline quality significantly. Rather, this effect is ascribed to the removal of surface adsorbed impurities (possibly hydroxyl groups) that cannot be detected by XRD.

Fig. 1(d) shows the NBE for samples annealed at temperatures ranging from 300 to $450^{\circ} \mathrm{C}$. From these spectra, five observations can be made: (i) two distinct peaks (with almost the same intensities) are seen at around $3.3630 \mathrm{eV}$ $\left(\mathrm{I}_{4}\right)$ and $3.3604 \mathrm{eV}\left(\mathrm{I}_{6 \mathrm{a}}\right)^{20,21}$ for the sample annealed at 

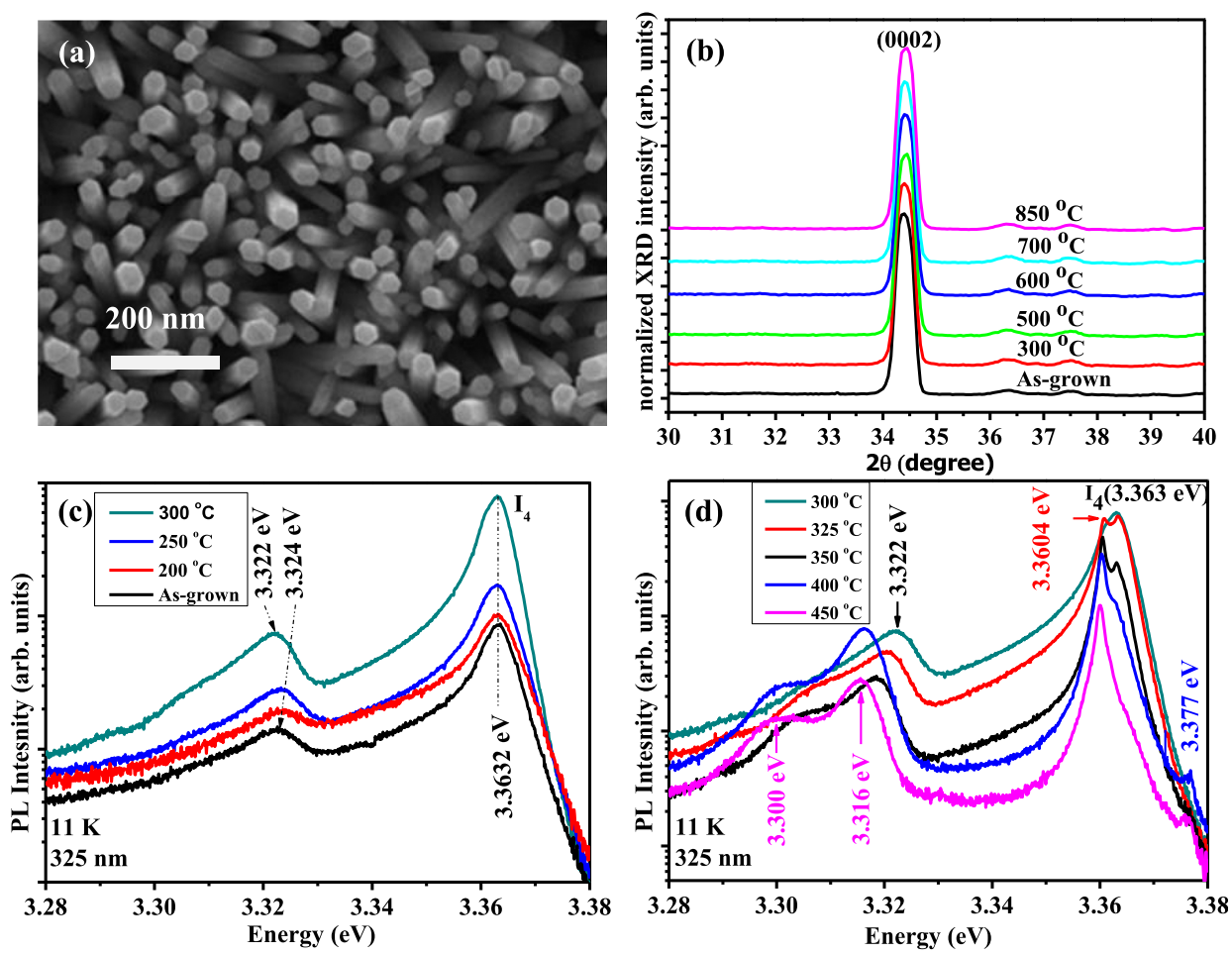

FIG. 1. (a) Typical SEM micrograph of the rods used in this study. (b) Normalized XRD spectra of as-grown sample and samples sequentially annealed at 300, 500, 600, 700 and $850^{\circ} \mathrm{C}$ in oxygen for $30 \mathrm{~min}$. (c) Steady state PL spectra of samples annealed at temperatures up to $300^{\circ} \mathrm{C}$. (d) Steady state PL spectra of samples annealed between $300^{\circ} \mathrm{C}$ and $450^{\circ} \mathrm{C}$. $325^{\circ} \mathrm{C}$; (ii) as the annealing temperature increases to $450{ }^{\circ} \mathrm{C}$, the intensity of $\mathrm{I}_{4}$ rapidly decreases and $\mathrm{I}_{6 \mathrm{a}}$ dominates the spectra; (iii) the strong decrease in the intensity of $\mathrm{I}_{4}$ is accompanied by the disappearance of the low energy asymmetric broadening of the bound exciton luminescence; (iv) longitudinal FX appears at around $3.3770 \mathrm{eV}$ (Ref. 21) for samples annealed above $400^{\circ} \mathrm{C}$; and (v) the defect-related line seen at $\sim 3.322 \mathrm{eV}$ for the sample annealed at $300{ }^{\circ} \mathrm{C}$ continues to red shift and stabilizes at $3.316 \mathrm{eV}$ for samples annealed above $400{ }^{\circ} \mathrm{C}$.

The above observations can be explained based on the removal of hydrogen related impurities during annealing. Hydrogen in $\mathrm{ZnO}$ can be incorporated in three known positions: (i) interstitially $\left(\mathrm{H}_{\mathrm{i}}\right)$ at the bond-centered site between $\mathrm{Zn}^{2+}$ and $\mathrm{O}^{-}$or at the anti-bonding site bound to the $\mathrm{O}^{-}$ ion, ${ }^{22,23}$ (ii) in an oxygen vacancy $\left(\mathrm{H}_{\mathrm{O}}\right),{ }^{22}$ and (iii) in the form of surface adsorbed $\mathrm{H}$ and species, such as $\mathrm{OH}$ and $\mathrm{H}_{2} \mathrm{O}{ }^{8,14}$ In bulk $\mathrm{ZnO}, \mathrm{H}_{\mathrm{i}}$ at the bond-centered $\left(\mathrm{H}_{\mathrm{BC}}\right)$ site (which gives rise to a $\mathrm{PL}$ line at $3.3601 \mathrm{eV}$ at $4.2 \mathrm{~K}$ (Ref. 24)) out-diffuses below $200{ }^{\circ} \mathrm{C},{ }^{24-26}$ whereas $\mathrm{H}_{\mathrm{O}}$ (which gives rise to the $3.3628 \mathrm{eV} \mathrm{PL}$ line $\left(\mathrm{I}_{4}\right)$ at $10 \mathrm{~K}$ ) has been found to anneal out at temperatures from $500{ }^{\circ} \mathrm{C}$ to $600{ }^{\circ}$ C. ${ }^{1}$ Surface adsorbed hydrogen-related impurities are also removed at these temperatures. For example, Lahiri et $a l{ }^{13}$ reported the removal of surface adsorbed $\mathrm{OH}$ from $\mathrm{H}_{2} \mathrm{~S}$ treated samples by annealing at a temperature of $427^{\circ} \mathrm{C}$ in vacuum. Yang et $a l^{8}$ also studied the origin of the surface recombination centers in solution grown $\mathrm{ZnO}$ nanorods arrays by XPS and reported the presence of $\mathrm{H}(\mathrm{O} 1 \mathrm{~s}$ peak at $528.4 \mathrm{eV})$ and $\mathrm{OH}(\mathrm{O} 1 \mathrm{~s}$ peak at $531.5 \mathrm{eV})$ on the surface of the nanorods, which could be removed after annealing at $500{ }^{\circ} \mathrm{C}$ in air. As the chemicals used and the growth conditions for the nanorods in this study are exactly the same as that of Yang et al., ${ }^{8}$ the same surface adsorbed impurities are expected. As clearly shown in Fig. 1(c), annealing below $300{ }^{\circ} \mathrm{C}$ increases the overall intensity of the luminescence, suggesting that annealing at these lower temperatures removes surface adsorbed impurities. Additionally, the hydrogen-related line $\left(\mathrm{I}_{4}\right)$ is removed only after annealing at $450{ }^{\circ} \mathrm{C}$ (see Fig. 1(d)) implying that in the case of nanorods, $\mathrm{H}_{\mathrm{O}}$ can be annealed out at $450{ }^{\circ} \mathrm{C}$. This is lower than the temperature reported by Lavrov et $a .^{26}$ for bulk $\mathrm{ZnO}$, but expected due to the small diameters of the rods.

The removal of hydrogen is also responsible for the narrowing of the dominant excitonic emission and the red-shift of the defect-related line. The asymmetric broadening on the low energy side of the low temperature bound exciton luminescence in $\operatorname{CdS}\left(n \sim 4 \times 10^{18} \mathrm{~cm}^{-3}\right)$ has previously been reported. ${ }^{27}$ Based on theoretical calculations and experimental observations, the asymmetric broadening, which is characteristic of heavily doped semiconductors, was explained in terms of the Stark effect, caused by high concentrations of ionized impurities in such material. ${ }^{27,28}$ It is worth mentioning that the highest PL intensity (with identical optics) is observed in the case of our sample annealed at $300{ }^{\circ} \mathrm{C}$ and that an ionized impurity concentration of $\sim 10^{18} \mathrm{~cm}^{-3}$ was obtained from a fit of the $\mathrm{I}_{4}$ line, using theory described in Refs. 27 and 28. Additionally, annealing studies using different ambient environments (hydrogen, vacuum, argon, and nitrogen (not shown in this paper)), having been repeated several times, showed that the highest room temperature PL intensity, irrespective of the annealing environment, was observed for samples annealed at $300^{\circ} \mathrm{C}$. For all annealing environments, the PL intensity increased with increasing annealing temperature up to $300^{\circ} \mathrm{C}$ and then decreased at temperatures above $300^{\circ} \mathrm{C}$. This result is suggested to be caused by interplay between two effects: the "optimal" removal of surface adsorbed impurities (causing non-radiative 
recombination) and the relative stability of $\mathrm{H}_{\mathrm{O}}$. This implies that for samples annealed below $350^{\circ} \mathrm{C}$, high concentrations of hydrogen donors will be present causing a strong Stark effect.

Finally, the gradual shift of the defect related line (from $\sim 3.324$ to $\sim 3.316 \mathrm{eV})$ and the accompanying transition ( $\sim 16 \mathrm{meV}$ lower in energy), for annealing temperature up to $450{ }^{\circ} \mathrm{C}$, is also suggested to be related to the removal of hydrogen from the sample. There is strong evidence in literature that the line (sometimes two lines) between 3.3 and $3.33 \mathrm{eV}$ arises from BSFs. For example, Schirra et al. ${ }^{29}$ studied two defect related lines (at 3.31 and $\sim 3.30 \mathrm{eV}$ ) in bulk and nanostructured $\mathrm{ZnO}$ using low-temperature cathodoluminescence (CL), temperature dependent PL, TEM, and high-resolution $\mathrm{x}$-ray diffraction and observed a line at $3.31 \mathrm{eV}$ at $10 \mathrm{~K}$ irrespective of the nature of the sample. In some samples they also observed a line at $\sim 3.30 \mathrm{eV}$. By correlating the structural data from TEM and SEM with spacially resolved, monochromatic CL, they concluded that the line observed at $3.31 \mathrm{eV}$ is associated with BSFs. The electronic nature of this transition was ascribed to free to bound $\left(\mathrm{e}, \mathrm{A}^{\mathrm{o}}\right)$, based on line-shape evolution in temperature dependent CL measurements. Furthermore, the line at $\sim 3.30 \mathrm{eV}$ was ascribed to a donor-acceptor pair (DAP) emission. The binding energy of the acceptor involved in both transitions was determined to be $\sim 130 \mathrm{meV}$. Thonke et al..$^{30}$ also studied the role of stacking faults in a doped and undoped bulk $\mathrm{ZnO}$ using $\mathrm{CL}$ with high spatial and wavelength resolution and temperature dependent PL. They concluded that lines at $3.314 \mathrm{eV}$ and at $3.30 \mathrm{eV}$ (at $15 \mathrm{~K}$ ) are associated with $\left(\mathrm{e}, \mathrm{A}^{\circ}\right)$ and DAP emissions, respectively, induced by BSFs. Similar to Schirra et al., ${ }^{29}$ Thonke et al. ${ }^{30}$ also reported an acceptor binding energy of $130 \mathrm{meV}$. Although the chemical origin of the acceptor is unknown, the $\mathrm{Zn}$ vacancy was suggested as a possible candidate by both. It is also important to point out that these two lines have different temperature dependencies. While the $\left(\mathrm{e}, \mathrm{A}^{\mathrm{o}}\right)$ line is quite stable with measurement temperature, the DAP line quenches at around $40 \mathrm{~K} \cdot{ }^{29-31}$ Also, in a previous paper from our group, very similar temperature dependencies of the two lines at almost identical energies ( $3.320 \mathrm{eV}$ and 3.305 at $2 \mathrm{~K}$ ) were reported for $\mathrm{ZnO}$ thin films grown by metal organic chemical vapor deposition (MOCVD) on GaAs substrate, although the chemical origin of the acceptor was incorrectly assigned. ${ }^{32}$ These observed abrupt decrease in the intensity of the DAP emission with temperature is consistent with the rapid ionization of the shallow donor, leaving the $\left(\mathrm{e}, \mathrm{A}^{\mathrm{o}}\right)$ recombination as the dominant mechanism.

More recently, Khranovskyy et al. ${ }^{5}$ reported a line at $3.329 \mathrm{eV}$ at $4 \mathrm{~K}$ in $\mathrm{ZnO}$ nanorods with a high concentration of $\mathrm{BSF}$ and ascribed it to emission from a quantum well (QW) formed by the segregation of zinc blende (ZB) material within the wurtzite (WZ) ZnO. These planar inclusions of $\mathrm{ZB} \mathrm{ZnO}$ in the normal WZ crystal have been theoretically shown to form type-II QWs with a valence/conduction band offset of $37 / 147 \mathrm{meV}^{33}$ The insertions of such regions result from the formation of BSFs perpendicular to the c-axis, as experimentally observed by Khranovskyy et al..$^{5}$ Theoretically, electrons are weakly confined in the well and the holes are located in the barriers of these structures. ${ }^{33}$ Also reported recently is the formation of a quantum wire at the intersection between a $3.8 \mathrm{~nm}$ thick $(\mathrm{Al}, \mathrm{Ga}) \mathrm{N} / \mathrm{GaN}$ quantum well and $\mathrm{BSFs}$, leading to radiative recombination of localized excitons. ${ }^{34}$ Although the energetic position reported by Khranovskyy et al. ${ }^{5}$ is considerably higher than what has been reported by Schirra et al. ${ }^{29}$ Thonke $e^{5}$ al. ${ }^{30}$ and also in this work, Khranovskyy et al. ${ }^{5}$ clearly demonstrated the presence of a high density of BSFs perpendicular to the c-axis. They also studied temperature and laser power dependent PL and concluded that the line has an excitonic nature. The recombination mechanism was ascribed to an indirect excitonic transition associated with electrons in the QW conduction band and holes localized near the BSF. Hence, these structures may certainly lead to radiative recombination in $\mathrm{ZnO}$.

In the present study, the lines observed at $\sim 3.316 \mathrm{eV}$ and $\sim 3.30 \mathrm{eV}$ are ascribed to $\left(\mathrm{e}, \mathrm{A}^{\circ}\right)$ and DAP emission, respectively, both associated with BSFs. This assignment was based on the similarity in peak energies and temperature dependencies presented by Schirra et al., ${ }^{29}$ Thonke et al., ${ }^{30}$ Shan et al., ${ }^{31}$ and previous temperature dependencies reported by this group (see Ref. 32). As can be seen from Figs. 1(a) and 1(b), these two lines both red shift as the annealing temperature increases from 300 to $450^{\circ} \mathrm{C}$. Interestingly, this coincides with the temperature range in which the hydrogen-related line $\left(\mathrm{I}_{4}\right)$ anneals out. For samples annealed above $450{ }^{\circ} \mathrm{C}$ (to be discussed presently), no further shift of these two lines was observed. Since a high concentration of hydrogen donors is expected for samples annealed at low temperatures, it seems plausible that the initial state of the electron (i.e., the conduction band edge) is shifted upward due to the Burstein-Moss effect, causing the $\left(\mathrm{e}, \mathrm{A}^{\mathrm{o}}\right)$ emission to appear at slightly higher energies for these samples. The high concentration of donors, assuming a constant BSF density, will cause the average separation between donors and acceptors to be reduced, resulting in the blue-shift in the DAP emission for low annealing temperatures.

Overall, the effect of annealing at moderate temperatures $\left(200-450^{\circ} \mathrm{C}\right)$ can be summarized as follows. For samples annealed below $300^{\circ} \mathrm{C}$, the strong increase in the PL intensity is attributed to the removal of surface adsorbed impurities. The high concentration of hydrogen donors persisting up to $\sim 300^{\circ} \mathrm{C}$ causes significant asymmetric broadening of the excitonic emission as a result of the Stark effect. For annealing temperatures above $300{ }^{\circ} \mathrm{C}$, hydrogen $\left(\mathrm{H}_{\mathrm{O}}\right)$ efficiently out-diffuses and is finally removed (i.e., below the detection limit of the PL system) at $450{ }^{\circ} \mathrm{C}$. The systematic removal of hydrogen is accompanied by a strong reduction in the asymmetric broadening on the lower energy side of the $\mathrm{I}_{4}$ line.

Fig. 2 presents the time resolved PL spectra for the asgrown sample (a) and for samples annealed at $300^{\circ} \mathrm{C}$ (b) and $400{ }^{\circ} \mathrm{C}(\mathrm{c})$. The spectra indicate the evolution of the PL after the passing of the excitation pulse. Immediately after the excitation pulse is switched off $(0 \mathrm{ps})$, the spectral features resemble those as seen in the steady-state PL, the only exceptions being the relatively weak BSF-related emission. This is due to the lower spectral resolution of the timeresolved PL spectrometer as compared with the steady-state 

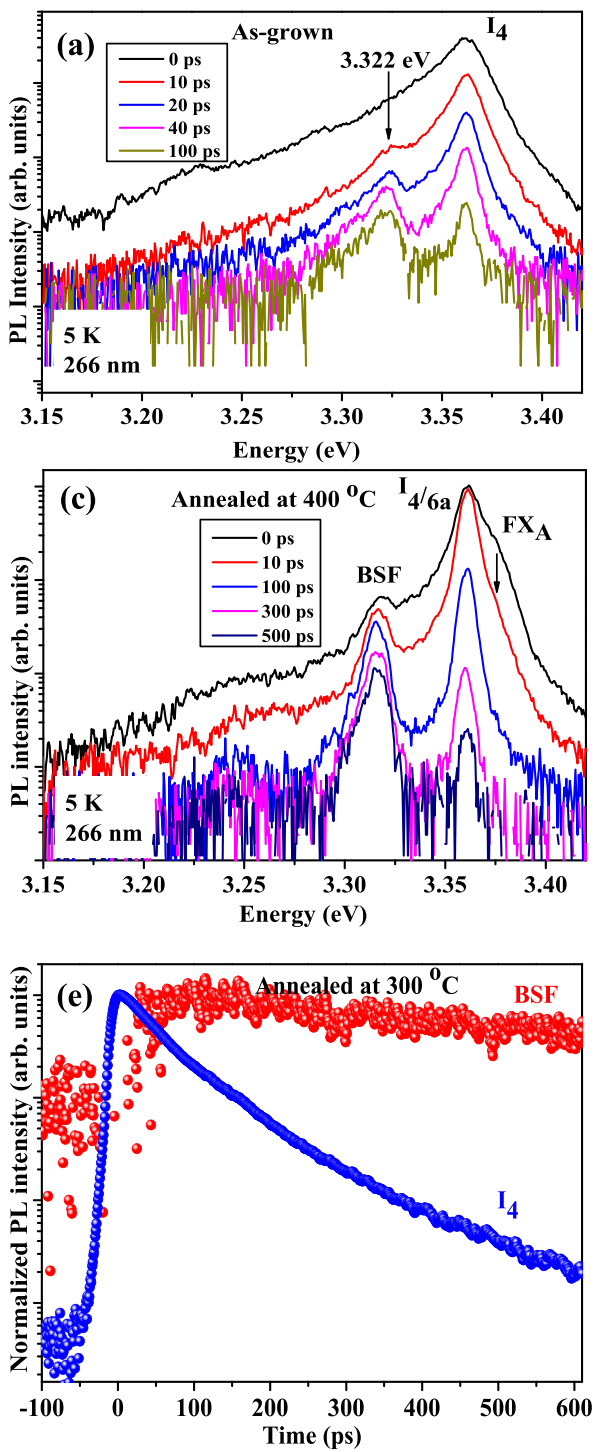
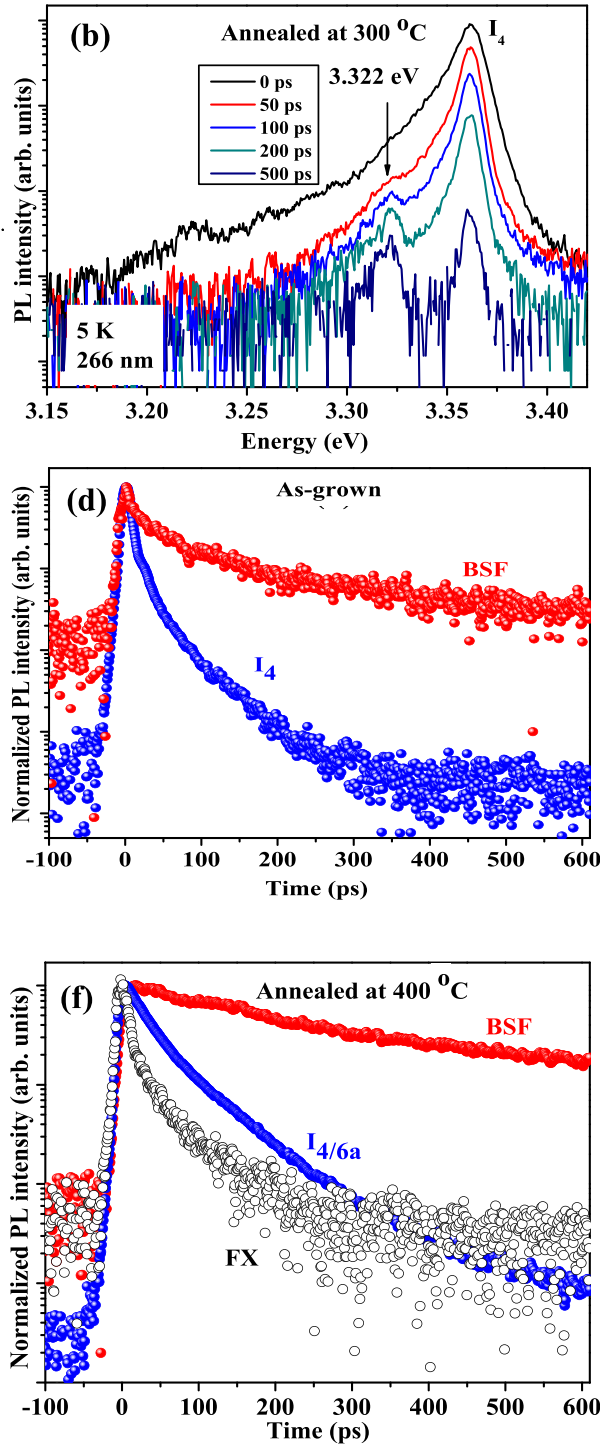

FIG. 2. Time-resolved PL spectra of samples annealed at moderate temperatures: (a) as-grown, (b) $300^{\circ} \mathrm{C}$, and (c) $400^{\circ} \mathrm{C}$. The corresponding background corrected and normalized PL transients for the dominant emission lines are shown in (d)-(f), respectively.
PL spectrometer. In Fig. 2, three trends can be distinguished: (i) the decay times increase with annealing temperature, (ii) the excitonic emission decays faster than the BSF-related $\mathrm{PL}$, and (iii) the FX emission is observed for the sample annealed at $400{ }^{\circ} \mathrm{C}$, and decays much faster than the other emission lines.

It is important to note that the excitonic PL intensity observed in steady state is linked to the luminescence decay time. For example, the PL intensity of the sample annealed at $300{ }^{\circ} \mathrm{C}$ is nine times higher than that of the as-grown sample, for which the shortest decay times are observed. This is ascribed to the relative contribution of non-radiative recombination in each sample. It is well known that the measured PL lifetime $\tau_{\mathrm{PL}}$ reflects contributions from radiative and nonradiative processes, so that $1 / \tau_{\mathrm{PL}}=1 / \tau_{\mathrm{r}}+1 / \tau_{\mathrm{nr}}$, where $\tau_{\mathrm{r}(\mathrm{nr})}$ denotes the radiative (non-radiative) lifetimes. Here, the shorter lifetime determines the overall decay rate. The shorter PL lifetime observed for the as-grown sample suggests that non-radiative recombination is dominant. The most probable reason would be the involvement of surface adsorbed impurities, the effect of which is discussed later.

Figs. 2(d)-2(f) show the corresponding background corrected and normalized PL transients, taken at the energy of the maximum of each of the dominant PL lines $\left(\mathrm{D}^{\circ} \mathrm{X}\right.$, $\mathrm{BSF}$, and FX). In most cases, the transients exhibit a bi-exponential decay, with a characteristic fast and slow components similar to earlier reports. ${ }^{3,9,10,18}$ The only exception is the decay of the BSF-related emission, for which the fast component could not unambiguously identified in the transients after annealing. The fast and slow components have been associated with recombination in the "near-surface" and "bulk" regions of the sample, respectively. 3,9,10,18 It can be seen that the relative contribution of each component varies from sample to sample and from transition to transition. For the as-grown sample, the decay characteristics of the $\mathrm{I}_{4}$ are dominated by the fast component. For the samples annealed at $300^{\circ} \mathrm{C}$ and $400{ }^{\circ} \mathrm{C}$ (Fig. 2(e)), the contribution from the fast component is significantly reduced. For the $400^{\circ} \mathrm{C}$-annealed sample, the FX line also shows a bi-exponential decay character. This transient decays much faster than the other two, and the fast component plays a more dominant role.

Figs. 3(a) and 3(b) show the steady state NBE PL spectra of samples annealed from $450{ }^{\circ} \mathrm{C}$ to $650{ }^{\circ} \mathrm{C}$ and from $650{ }^{\circ} \mathrm{C}$ to $850^{\circ} \mathrm{C}$, respectively. As can be seen from these spectra, two exciton lines at $3.377 \mathrm{eV}(\mathrm{FX})$ and at $3.3604 \mathrm{eV}$ $\left(\mathrm{I}_{6 \mathrm{a}}\right)$, as well as three defect-related lines at around $\sim 3.332 \mathrm{eV}$, 

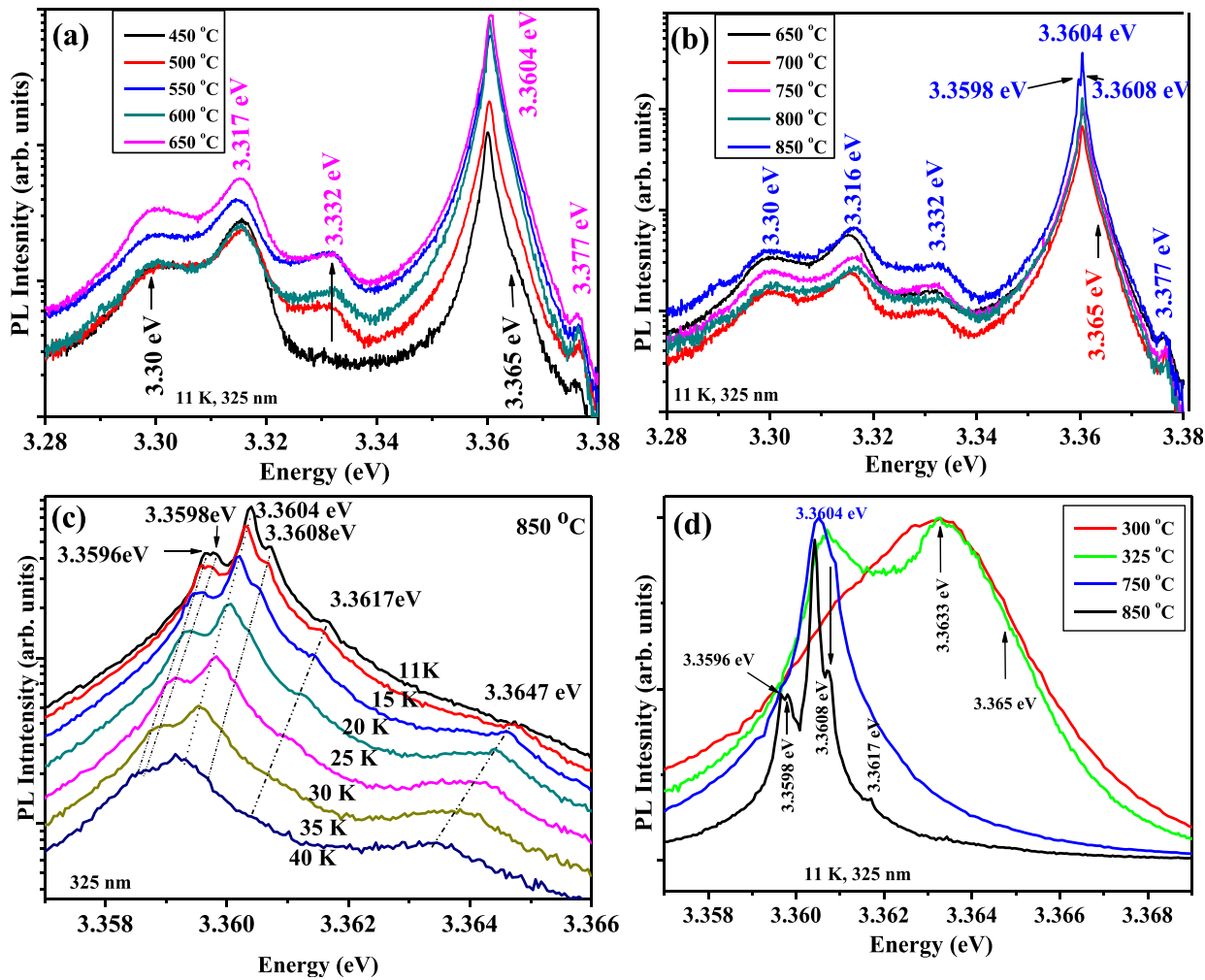

FIG. 3. Low temperature steady state NBE spectra of samples annealed at higher temperatures: (a) $450^{\circ} \mathrm{C}-650^{\circ} \mathrm{C}$, (b) $650^{\circ} \mathrm{C}-850^{\circ} \mathrm{C}$, (c) temperature dependent PL spectra of sample annealed at $850^{\circ} \mathrm{C}$, and (d) normalized steady state PL spectra of selected samples. $\sim 3.316 \mathrm{eV}$ (BSF) and $\sim 3.30 \mathrm{eV}$ (DAP) are observed up to an annealing temperature of $850^{\circ} \mathrm{C}$. In all cases, the $\mathrm{I}_{6 \mathrm{a}}$ line dominates the spectra. The peak at $\sim 3.332 \mathrm{eV}$, which is energetically very close to the peak ascribed to BSF-induced quantum wells by Khranovskyy et al., ${ }^{5}$ has also been assigned to an exciton bound to a structural defect, ${ }^{1}$ and is often referred to as a $\mathrm{Y}$-line. Note that this line only evolves after annealing at $500^{\circ} \mathrm{C}$. In addition, the BSF-related line at $\sim 3.316 \mathrm{eV}$ is also observed in all cases and its position does not shift, unlike in the case of low temperature annealed samples. In the case of the sample annealed at $850^{\circ} \mathrm{C}$, multiple bound excitons, including peaks at $3.3647 \mathrm{eV}, 3.3617 \mathrm{eV}$, $3.3608 \mathrm{eV}, \quad 3.3604 \mathrm{eV}, \quad 3.3598 \mathrm{eV}$, and $3.3596 \mathrm{eV}$, are observed (Fig. 3(c)). The dominant peak $\left(3.3604 \mathrm{eV}, \mathrm{I}_{6 \mathrm{a}}\right)$ has a FWHM of approximately $0.2 \mathrm{meV}$, indicating a high quality sample.

As some of these emission lines are only activated above $15 \mathrm{~K}$, temperature dependent PL spectra for the sample annealed at $850{ }^{\circ} \mathrm{C}$, taken between $11 \mathrm{~K}$ and $40 \mathrm{~K}$, are included in Fig. 3(c). Notice that the FX line is not shown, but as usual its intensity increases with increasing measurement temperature. Starting from the high energy side, the lines at $3.3617 \mathrm{eV}, 3.3608 \mathrm{eV}, 3.3604 \mathrm{eV}, 3.3598 \mathrm{eV}$, and $3.3596 \mathrm{eV}$ are ascribed to $\mathrm{I}_{5}, \mathrm{I}_{6}, \mathrm{I}_{6 \mathrm{a}}, \mathrm{I}_{8}$, and $\mathrm{I}_{8 \mathrm{a}}$, respectively. ${ }^{1,21}$ A line at $3.3647 \mathrm{eV}$ becomes evident above $15 \mathrm{~K}$. All of these $\mathrm{D}^{\circ} \mathrm{X}$ lines are well known from literature (see Refs. 21 and 35). However, the origin of the line at around $3.3647 \mathrm{eV}$ is somewhat controversial, with two possible assignments $^{10}$ often encountered in literature: (i) $\mathrm{D}^{\circ} \mathrm{X}$ (unspecified chemical origin) and (ii) excitons localized on surface defects. Teke et al. ${ }^{4}$ and Robin et al. ${ }^{36}$ have observed this emission line in the $10 \mathrm{~K}$ PL of bulk $\mathrm{ZnO}$ and assigned it to an exciton bound to a neutral donor (labeled $\mathrm{D}_{4}{ }^{\circ} \mathrm{X}_{4}$ ).
Reparaz et al. ${ }^{10}$ reported that the intensity of this line increases with a decrease in the size of nanorods and also assigned it to a $\mathrm{D}^{\circ} \mathrm{X}$. Alternatively, Richters et al. ${ }^{37}$ and Wischmeier et $a l .{ }^{38}$ observed the same line at $5 \mathrm{~K}$ in catalyst-assisted physical vapor deposited nanorods and assigned it to surface bound excitons (SX). Dumcenco et al. ${ }^{2}$ also assigned a line at $3.367 \mathrm{eV}($ at $9 \mathrm{~K}$ ) in micro-rods grown by catalyst-assisted thermal evaporation, to surface bound excitons.

As can be seen from the temperature dependent measurements, the intensity of this line increases with increasing temperature. SX emission originates from an exciton trapped at local potential minima near the surface. The normal behavior of the neutral donor bound exciton lines as the temperature increases is a rapid quenching due to the thermal delocalization of excitons, as well as the ionization of the donors. In contrast, our experimental outcome clearly shows that the intensity of this line increases with measurement temperature (see Fig. 3(c)). Hence, the assignment of this line as $\mathrm{D}^{\circ} \mathrm{X}$ is unlikely. It is believed that this line exists in the spectra of all the samples (but is not resolvable for asgrown and low temperature annealed samples due to the broadness of the $\mathrm{I}_{4}$-line). A recent report by Biswas et al. ${ }^{39}$ relates the surface bound exciton to surface adsorbed $\mathrm{OH}$ species. The observation of emission from this source, even after annealing at elevated temperatures in the present work, is not inconsistent with our explanation for the improvement in the PL response of low temperature annealed samples earlier (i.e., that low temperature annealing removes surface adsorbed species, thus enhancing excitonic recombination in the bulk of the rods). The re-adsorption of species like $\mathrm{OH}$-groups when the samples are exposed to ambient after high temperature annealing, is inevitable. 
Fig. 3(d) presents normalized PL spectra of representative samples in the energy range between $3.357 \mathrm{eV}$ and $3.369 \mathrm{eV}$ for comparison. The change in line shape and the evolution of different lines with annealing temperature are striking in this figure, in which a linear intensity scale has been employed.

Fig. 4 presents time resolved PL spectra ((a)-(c)) and PL transients ((d)-(f)) of the predominant $\mathrm{D}^{\circ} \mathrm{X}$ line, BSF, and FX emission for samples annealed at $600^{\circ} \mathrm{C}, 750^{\circ} \mathrm{C}$, and $850^{\circ} \mathrm{C}$, respectively. As can be seen from the time resolved spectra, for delay times longer than $400 \mathrm{ps}$, the PL for samples annealed at these higher temperatures is qualitatively the same as for the sample annealed at $400^{\circ} \mathrm{C}$ (Fig. 2(c)). It is also important to note that in all cases, including the samples annealed at $400{ }^{\circ} \mathrm{C}$, the $\mathrm{D}^{\circ} \mathrm{X}$ lines quench faster than the BSF line, while the FX line quenches strongly already within the first 10 ps (i.e., on a time scale similar to the temporal resolution of the system).

The PL transients for the dominant emission lines (Figs. 4(d)-4(f)) also clearly show the differences in the decay rates of different emission lines from the same sample. In all cases, the FX signal decays fastest, followed by the
$\mathrm{D}^{\circ} \mathrm{X}$ and BSF lines, respectively. As observed in the case of samples annealed at lower temperatures (Figs. 2(e) and 2(f)), the contribution from the fast component to the biexponential decay curves of the excitonic emission for these samples further decreases with increasing annealing temperature.

A summary of the decay characteristics of the different recombination lines observed in the samples is presented in Fig. 5. In these graphs, the experimental results (symbols) are fitted with bi-exponential decays (solid lines) of the form $I(t)=A_{s} \exp \left(-t / \tau_{s}\right)+A_{b} \exp \left(-t / \tau_{b}\right)$. For the BSF-related emission in annealed samples (Fig. 5(c)), only a single exponential decay was assumed. The vertical dotted lines in Figs. 5(a) and 5(b) illustrate the times after which the slow component starts to dominate the decay of the excitonic emission lines. The best-fit values for the decay times are shown in Fig. 5(d).

As discussed above, the contribution from the fast component to each emission line tends to decrease with increasing annealing temperature, in agreement with earlier findings reported in references. ${ }^{8-11,18}$ The fast components extracted for the $\mathrm{FX}$ and the $\mathrm{D}^{\circ} \mathrm{X}$ emission (for the as-grown sample in
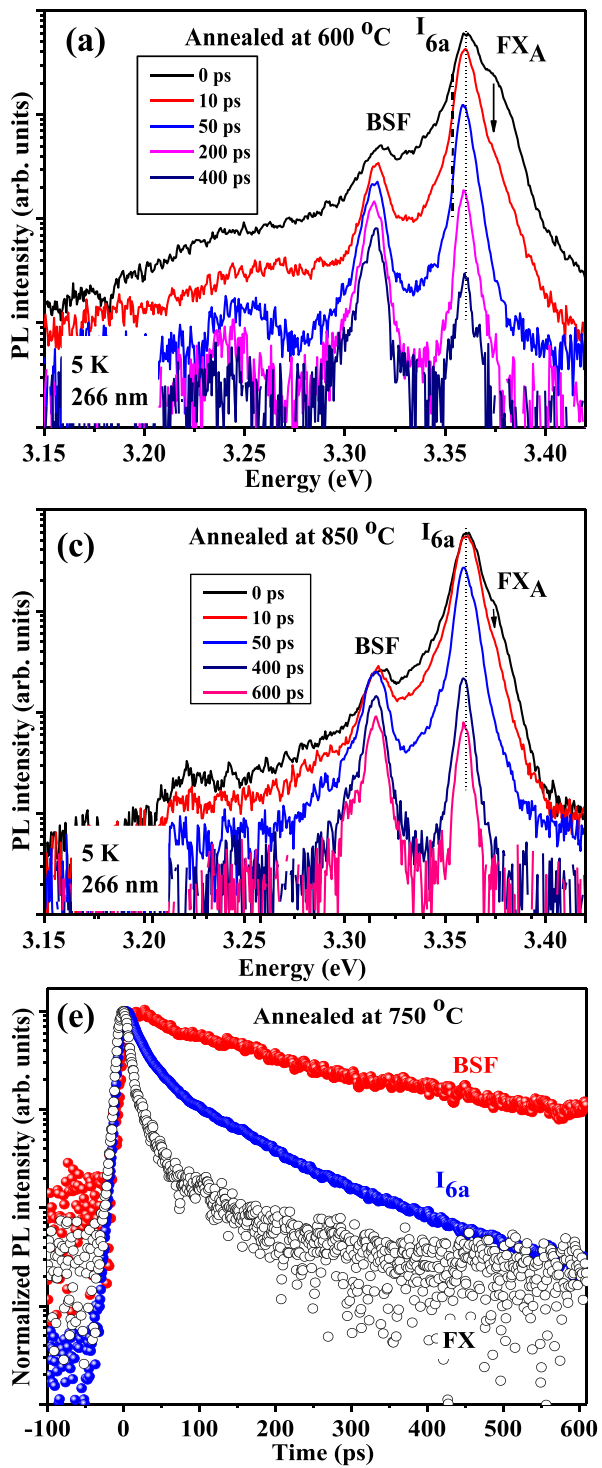
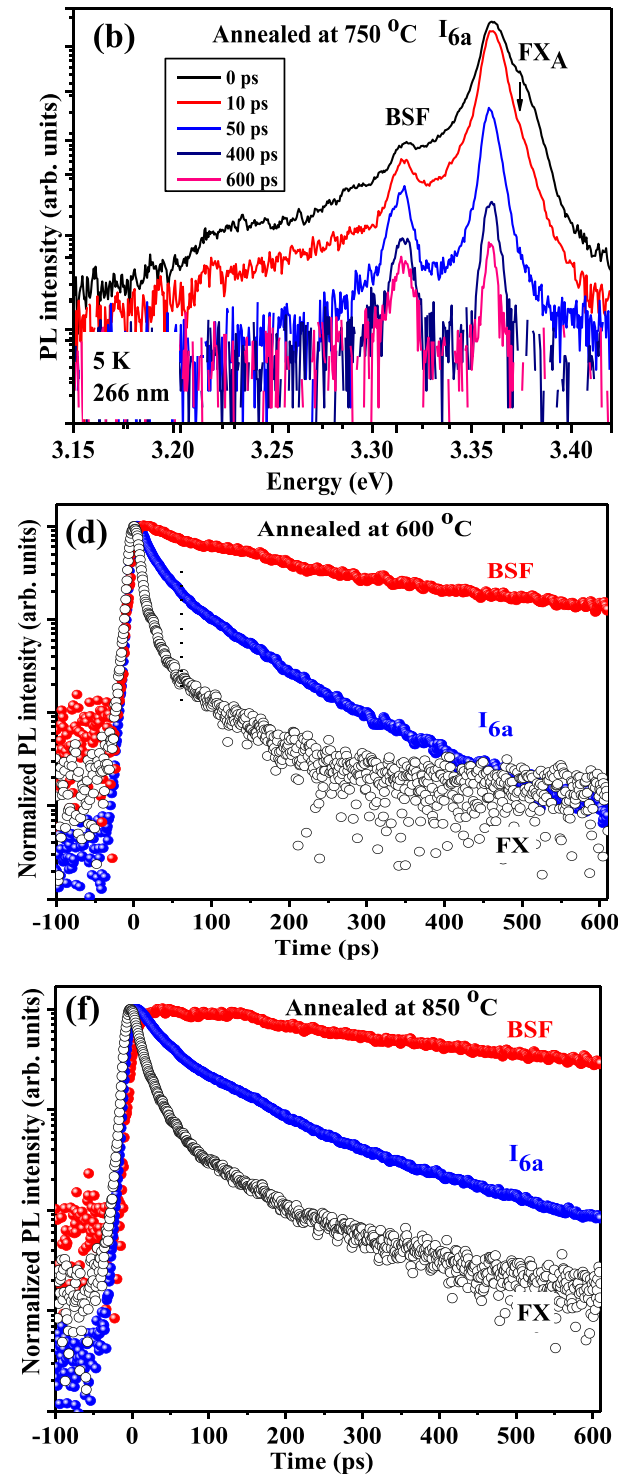

FIG. 4. Time delayed PL spectra of samples annealed at higher temperatures: (a) $600^{\circ} \mathrm{C}$, (b) $750^{\circ} \mathrm{C}$, and (c) $850^{\circ} \mathrm{C}$. The corresponding background corrected and normalized decay curves of the dominant emission lines are shown in (d)-(f), respectively. 

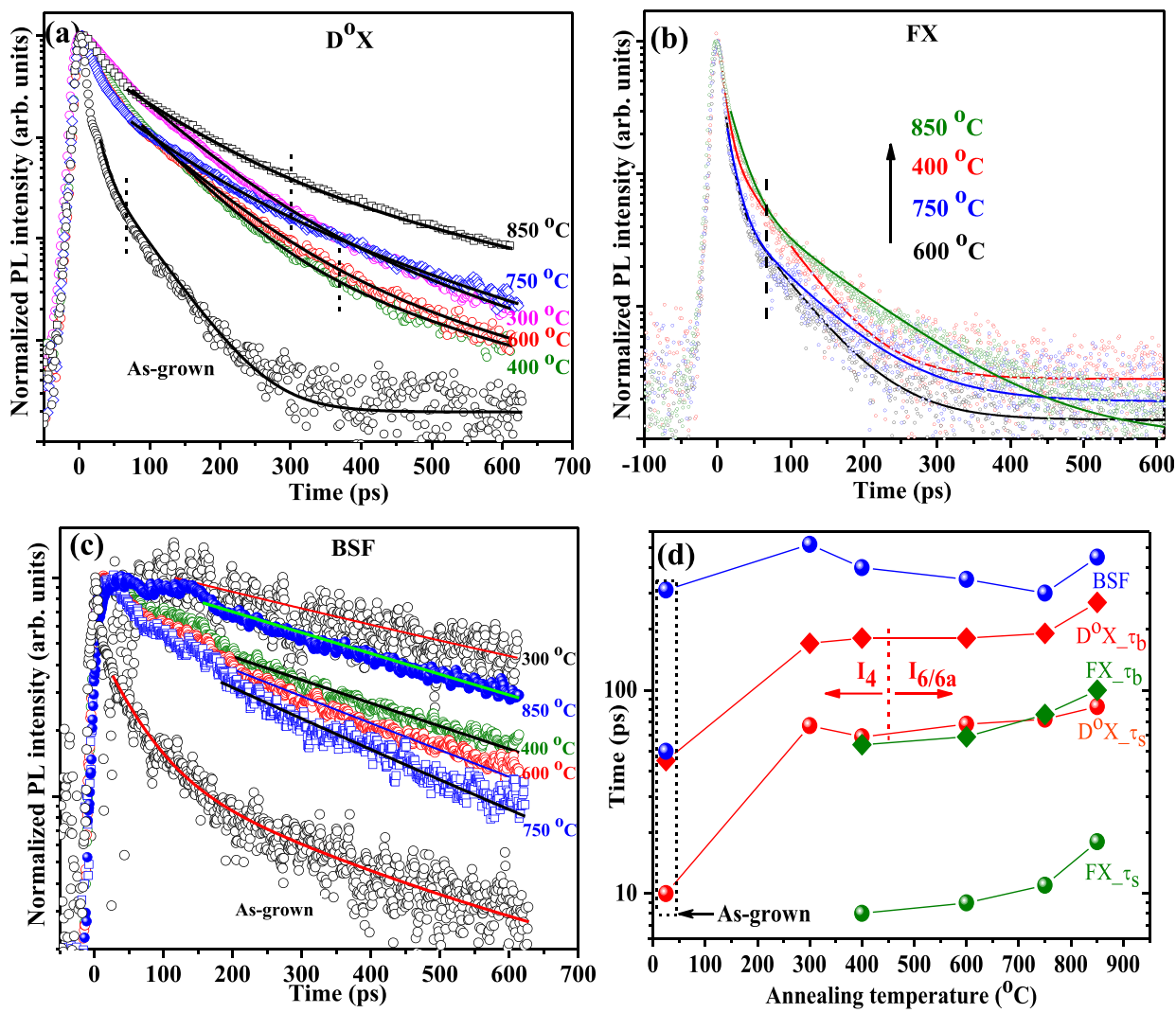

FIG. 5. Time-dependent PL intensity (normalized and background corrected) of the dominant emission lines from the samples annealed at different temperatures: (a) $\mathrm{D}^{\circ} \mathrm{X}$, (b) FX, and (c) BSF lines. The symbols are experimental data, while the solid lines represent fitted curves assuming either bi-exponential or mono-exponential decays (in the case of the BSF-related emission for the annealed samples). (d) Best-fit values obtained for $\tau_{\mathrm{b}}$ and $\tau_{\mathrm{s}}$ as a function of annealing temperature. All PL measurements were obtained with a laser power of $5 \mu \mathrm{W}$. the latter case) are similar to the temporal resolution of the system and therefore contain considerable uncertainty. It is clear that there is an overall trend of an increase in the bulk (slow) lifetime component for the bound excitonic emission, with the strongest effect observed following a $300{ }^{\circ} \mathrm{C}$ anneal. The same effect is observed for the fast component. Both the slow and fast components of the free exciton tend to increase for annealing temperatures greater than $400{ }^{\circ} \mathrm{C}$. The BSFrelated PL lifetime is rather insensitive to annealing temperature, the only effect being the disappearance of the contribution from the fast component upon annealing.

With reference to the above results, Zhao and coworkers 8,9 studied the effect of annealing at $500{ }^{\circ} \mathrm{C}$ on the decay of the bound exciton emission $(1.8 \mathrm{~K})$ for $\mathrm{ZnO}$ nanorods grown using CBD and concluded that annealing at this temperature did not affect $\tau_{\mathrm{b}}$, relative to the value (95 ps) measured for an as-grown sample. In the present study, even if one assumes that the slight increase in $\tau_{\mathrm{b}}\left(\right.$ for $\mathrm{D}^{\circ} \mathrm{X}$ ) for annealing temperatures above $300{ }^{\circ} \mathrm{C}$ is negligible, the bulk lifetime is considerably enhanced compared with that for the as-grown sample. As in the work of Zhao et al., who showed an increase in $\tau_{\mathrm{s}}$ upon annealing at $500{ }^{\circ} \mathrm{C}$, the fast component extracted in the present study for the $\mathrm{D}^{\circ} \mathrm{X}$ emission also increases significantly after annealing, as would be expected from a reduction in surface recombination. The enhancement in the values of $\tau_{\mathrm{b}}$ (for both excitonic transitions) for samples annealed above $600{ }^{\circ} \mathrm{C}$ in this study is suggested to result from an improvement in crystal quality (due to the annealing out of native defects). Indeed, Mohanta et al. ${ }^{40}$ reported a radiative lifetime of about 432 ps from a donor bound exciton (at an emission energy of $3.358 \mathrm{eV}$ at $4.3 \mathrm{~K}$ ) in $\mathrm{ZnO}$ nanorods fabricated by MOCVD on GaN. This lifetime is much longer than what is typically reported for solution grown nanorods and they ascribed the improvement to better crystal quality.

To conclude, it can be seen that the fast decay component is strongly influenced already after annealing at low temperature $\left(300^{\circ} \mathrm{C}\right)$. This clearly illustrates that the surface dominates in the case of the as-grown sample. As stated above and suggested by different researchers, the surface of solution grown $\mathrm{ZnO}$ nanorods is dominated by adsorbed impurities. $8,13-16,22,26$ As shown in this study, these can be removed by annealing at a moderate temperature of $300^{\circ} \mathrm{C}$. The more dominant role of the fast component to the kinetics of recombination for the $\mathrm{FX}$ and $\mathrm{D}^{\circ} \mathrm{X}$ lines at lower annealing temperatures is therefore ascribed to the effect of "near-surface" recombination, as suggested by Chen et al. ${ }^{3}$ and Zhao et al., ${ }^{9}$ while the slow component is ascribed to recombination in the "bulk." The interplay between surface and bulk effects is discussed below.

\section{DISCUSSION}

All experimental observations can be explained in terms of near surface band bending arising from surface adsorbed impurities. It is well known that chemisorption of surface impurities at the $\mathrm{ZnO}$ surface causes an upward band bending by capturing electrons in regions near the surface. ${ }^{8,9,12,18,37} \mathrm{As}$ a result, a negative surface charge is generated, which is counterbalanced by a positive space charge originating from ionized donors within a depletion width away from the surface, thus ensuring overall charge neutrality. ${ }^{18}$ Consequently, a built-in electric field is produced across the depletion width, which will strongly influence the recombination processes in 
$\mathrm{ZnO}$ nanostructures. ${ }^{8}$ Upon excitation, the photo-generated electrons and holes near the surface will drift in opposite directions across the depletion region. ${ }^{8,9,12,18,37}$ As a result, the overlap of the wave-functions of the separated electrons and holes will decrease, lowering the probability of radiative recombination and increasing the probability of surface-statemediated non-radiative processes. In addition, the penetration depth of the laser $(266 \mathrm{~nm})$ used in this study is only about $50 \mathrm{~nm},{ }^{3}$ whereas the depletion width in nanorods grown using the same method has been reported to be around $69 \mathrm{~nm} .{ }^{18}$ However, the actual depth of the recombination region is significantly larger and is determined by the diffusion lengths of the photo-excited carriers, which is typically several $\mu \mathrm{m}$ in bulk material. $^{3}$

From both the steady state (Fig. 1(c)) and TRPL (Figs. 2(a) and 2(d)), it can be seen that no FX emission is observed and that the intensities of both the $\mathrm{D}^{\circ} \mathrm{X}$ and $\mathrm{BSF}$ emission lines in the as-grown sample are relatively small. In addition, for both lines, the decay profiles are dominated by the fast component (ascribed to the effect of near surface recombination). This suggests that excitation in the as-grown sample occurs predominantly inside the depletion region, which will significantly reduce the probability of the formation of free excitons, resulting in the dominance of non-radiative surface recombination. Carriers that are able to diffuse to regions of weaker electric field will preferably recombine through impurity states (caused by hydrogen) due to the high concentration of these in as-grown and low-temperature annealed materials. The bound exciton and BSF recombination are naturally still influenced by the proximity of the surfaces in these nano structures, due to the transfer of carriers to surface states, which will shorten the recombination lifetimes. ${ }^{3}$

The strong increase in intensity of the $\mathrm{D}^{\circ} \mathrm{X}$ line upon annealing at temperatures up to $300^{\circ} \mathrm{C}$ (Fig. 1(b)) is indicative of the removal of most surface adsorbed impurities, causing a reduction in the depletion width and near surface band bending, while the emergence of the FX line after annealing at $400{ }^{\circ} \mathrm{C}$, is ascribed to the reduction in the concentration of hydrogen in the material, which will reduce the probability of excitons being localized on this impurity.

\section{CONCLUSION}

In conclusion, both steady state and time-resolved PL spectroscopies were employed to evaluate the recombination dynamics of shallow neutral donor bound excitons, free excitons, and electrons at stacking faults in solution grown $\mathrm{ZnO}$ nanorods. The effect of annealing on the decay profiles of the observed transition lines was studied. A systematic removal of $\mathrm{I}_{4}$ after annealing at $450^{\circ} \mathrm{C}$ and the domination of $\mathrm{I}_{6 \mathrm{a}}$ in the low temperature PL spectra were clearly illustrated using steady state PL. The transient properties of the $\mathrm{I}_{4}, \mathrm{I}_{6 / 6}$ a, free exciton, and stacking fault-related emission were studied as a function of annealing temperature. For all exciton emission lines, a bi-exponential decay profile with characteristic fast and slow components was observed upon annealing and associated with recombination in the "near-surface" and "bulk" regions of the rods, respectively. The domination of the fast component in the case of as-grown and low temperature annealed samples, a suppression of the effects of surface mediated recombination for samples annealed above $400^{\circ} \mathrm{C}$, and an overall enhancement in crystal quality for samples annealed at around $850^{\circ} \mathrm{C}$ were shown.

\section{ACKNOWLEDGMENTS}

This work is based upon research supported by the South Africa Research Chairs Initiative of the Department of Science and Technology and the National Research Foundation (NRF), South Africa. The financial support from post-doctoral fellowship at Nelson Mandela Metropolitan University (NMMU), and Swedish-South Africa research collaboration are also gratefully acknowledged.

${ }^{1}$ B. K. Meyer, H. Alves, D. M. Hofmann, W. Kriegseis, D. Forster, F. Bertram, J. Christen, A. Hoffmann, M. Straßburg, M. A. Dworzak, U. Haboeck, and A. V. Rodina, Phys. Status Solidi B 241, 231 (2004).

${ }^{2}$ D. O. Dumcenco, Y. S. Huang, D. H. Kuo, and K. K. Tiong, J. Lumin. 132, 1890 (2012).

${ }^{3}$ S. L. Chen, W. M. Chen, and I. A. Buyanova, Appl. Phys. Lett. 102, 121103 (2013).

${ }^{4}$ A. Teke, U. Ozgur, S. Dogen, X. Gu, and H. Morkoc, Phys. Rev. B 70, 195207 (2004).

${ }^{5}$ V. Khranovskyy, A. M. Glushenkov, Y. Chen, A. Khalid, H. Zhang, L. Hultman, B. Monemar, and R. Yakimova, Nanotechnology 24, 215202 (2013).

${ }^{6}$ F. Bertram, J. Christen, A. Dadgar, and A. Krost, Appl. Phys. Lett. 90, 041917 (2007).

${ }^{7}$ M. R. Wagner, G. Callsen, J. S. Reparaz, J.-H. Schulze, R. Kirste, M. Cobet, I. A. Ostapenko, S. Rodt, C. Nenstiel, M. Kaiser, A. Hoffmann, A. V. Rodina, and M. R. Phillips, Phys. Rev. B 84, 035313 (2011).

${ }^{8}$ L. L. Yang, Q. X. Zhao, M. Willander, X. J. Liu, M. Fahlman, and J. H. Yang, Appl. Surf. Sci. 256, 3592 (2010).

${ }^{9}$ Q. X. Zhao, L. L. Yang, M. Willander, B. E. Sernelius, and P. O. Holtz, J. Appl. Phys. 104, 073526 (2008).

${ }^{10}$ J. S. Reparaz, F. Guell, M. R. Wagner, A. Hoffmann, A. Cornet, and J. R. Morante, Appl. Phys. Lett. 96, 053105 (2010).

${ }^{11}$ S. Hong, T. Joo, W. Park II, Y. Ho Jun, and G.-C. Yi, Appl. Phys. Lett. 83, 4157 (2003).

${ }^{12}$ H. Y. Shih, T. T. Chen, Y. C. Chen, T. H. Lin, and L. W. Chang, Appl. Phys. Lett. 94, 021908 (2009).

${ }^{13}$ J. Lahiri, S. Senanayake, and M. Batzill, Phys. Rev. B 78, 155414 (2008).

${ }^{14}$ C. Woll, Prog. Surf. Sci. 82, 55 (2007).

${ }^{15}$ B. Meyer, Phys. Rev. B 69, 045416 (2004).

${ }^{16}$ O. Dulub, U. Diebold, and G. Kresse, Phys. Rev. Lett. 90, 016102 (2003).

${ }^{17}$ W. Z. Liu, H. Y. Xu, J. G. Ma, C. Y. Liu, and Y. X. Liu, Appl. Phys. Lett. 100, 203101 (2012).

${ }^{18}$ L. L. Yang, Q. X. Zhao, M. Q. Israr, J. R. Sadaf, M. Willander, G. Pozina, and J. H. Yang, J. Appl. Phys. 108, 103513 (2010).

${ }^{19}$ Z. N. Urgessa, O. S. Oluwafemi, E. J. Olivier, J. H. Neethling, and J. R. Botha, J. Alloys Compd. 580, 120 (2013).

${ }^{20}$ B. K. Meyer, J. Sann, S. Lautenschläger, M. R. Wagner, and A. Hoffmann, Phys. Rev. B 76, 184120 (2007).

${ }^{21}$ B. K. Meyer, J. Sann, D. M. Hofmann, C. Neumann, and A. Zeuner, Semicond. Sci. Technol. 20, S62 (2005).

${ }^{22}$ E. V. Lavrov, J. Weber, F. Borrnert, C. G. Van de Walle, and R. Helbig, Phys. Rev. B 66, 165205 (2002).

${ }^{23}$ C. G. Van de Walle and J. Neugebauer, Nature 423, 626 (2003).

${ }^{24}$ M.-H. Du and K. Biswas, Phys. Rev. Lett. 106, 115502 (2011).

${ }^{25}$ G. Alvin Shi, M. Saboktakin, M. Stavola, and S. J. Pearton, Appl. Phys. Lett. 85, 5601 (2004).

${ }^{26}$ E. V. Lavrov, F. Herklotz, and J. Weber, Phys. Rev. B 79, 165210 (2009).

${ }^{27}$ K. Hiroshi, S. Shigeo, T. Seizo, and M. Kazuo, J. Phys. Soc. Jpn. 28, 110 (1970).

${ }^{28}$ H. Hanamura, J. Phys. Soc. Jpn. 28, 120 (1970).

${ }^{29}$ M. Schirra, R. Schneider, A. Reiser, G. M. Prinz, M. Feneberg, J. Biskupek, U. Kaiser, C. E. Krill, K. Thonke, and R. Sauer, Phys. Rev. B 77, 125215 (2008).

${ }^{30}$ K. Thonke, M. Schirra, R. Schneider, A. Reiser, G. M. Prinz, M. Feneberg, J. Biskupek, U. Kaiser, and R. Sauer, Phys. Status Solidi B 247, 1464 (2010). 
${ }^{31}$ C. X. Shan, Z. Liu, and S. K. Hark, Appl. Phys. Lett. 92, 073103 (2008).

${ }^{32}$ J. R. Botha, K. T. Roro, C. Weichsel, A. W. R. Leitch, and J. Weber, Superlattices Microstruct. 42, 26 (2007).

${ }^{33}$ Y. Yan, G. M. Dalpian, M. M. Al-Jassim, and S.-H. Wei, Phys. Rev. B 70, 193206 (2004).

${ }^{34}$ P. Corfdir, P. Lefebvre, L. Balet, S. Sonderegger, A. Dussaigne, T. Zhu, D. Martin, J.-D. Ganière, N. Grandjean, and B. Deveaud-Plédran, J. Appl. Phys. 107, 043524 (2010).

${ }^{35}$ U. Uzgur, Y. I. Alivov, C. Liu, A. Teke, M. A. Reshchikov, S. Dogan, V. Avrutin, S. J. Cho, and H. Morkoc, J. Appl. Phys. 98, 041301 (2005).
${ }^{36}$ I. C. Robin, C. Tavares, J. Rothman, and G. Feuillet, J. Korean Phys. Soc. 53, 2877 (2008)

${ }^{37}$ J.-P. Richters, T. Voss, D. S. Kim, R. Scholz, and M. Zacharias, Nanotechnology 19, 305202 (2008).

${ }^{38} \mathrm{~L}$. Wischmeier, T. Voss, I. Rückmann, J. Gutowski, A. C. Mofor, A. Bakin, and A. Waag, Phys. Rev. B 74, 195333 (2006).

${ }^{39}$ M. Biswas, Y.-S. Jung, H.-K. Kim, K. Rappan Kumar, G. J. Hughes, S. Newcomb, M. O. Henry, and E. McGlynn, Phys. Rev. B 83, 235320 (2011). ${ }^{40}$ S. K. Mohanta, S. Tripathy, X. H. Zhang, D. C. Kim, C. B. Soh, A. M. Yong, W. Liu, and H. K. Cho, Appl. Phys. Lett. 94, 041901 (2009). 